\title{
Use of hypnotherapy in controlling post stroke psychological and emotional
}

changes.

Keele

Sanyal $\mathbf{R}^{1}$, Muddegowda $\mathbf{G}^{1}$, Natarajan $\mathbf{I}^{1}$, Ferdinand $\mathbf{P}^{1}$, Roffe $\mathbf{C}^{1}$

The treating physician informed the patient about the hypnotherapy option and consent was taken prior to initiating hypnotherapy. The rational for the therapy was explained to the patient. The study was approved by the medical ethics committee of the trust.

Mood and emotional disturbances are frequent symptoms following stroke. in stroke survivors. These symptoms can cause significant distress for both the patients and their caregivers, and negatively influence patient quality of life and recovery. The following are the most important mood/emotional disturbances; post-stroke depression (PSD), post-stroke anxiety, post-stroke emotional incontinence (PSEI), post-stroke anger proneness (PSAP), and post-stroke fatigue (PSF) . These emotional disturbances have been shown, in clinical studies, to cause negative impacts on patients' clinical outcomes. PSD, for example, negatively influences later functional outcomes after stroke, decreases quality of life, leads to less efficient use of rehabilitation services and increases mortality. Patients with PSF are more often unemployed, change their jobs and fail to return to previous jobs than those without PSF. The overall negative impacts of PSEI and PSAP are less marked than those of PSD, they still lead to distress and embarrassment, impair certain domains of patients' quality of life, and increase caregiver burden. These mood and emotional disturbances can be treated or prevented by various methods, including pharmacological therapy. Unfortunately there is still less awareness among stroke teams to identify these important symptoms and manage them appropriately. There is clinical evidence for the use of hypnotherapy in treating these conditions in non-stroke patients.

The following is the report on the case series of patients treated with hypnotherapy with these conditions following stroke.

METHODS

Recruitment of patients:

Between March 2014 and February 2018, successive patients diagnosed with psychological and

emotional changes following stroke were offered hypnotherapy for improvement of the symptoms.

The post stroke psychological or emotional symptoms were diagnosed in the first follow-up

appointment in stroke clinic. The symptoms were either volunteered by the patient or carer during

consultation or the symptoms were established by using the post stroke check list.

\section{Inclusion criteria}

- Patient with diagnosis of functional stroke, confirmed by above mentioned criteria

- Age greater than 18 years.

- Symptoms persisting after 4 weeks of stroke and present during out patient follow-up appointment

- No problem in speaking and understanding English.

\section{Exclusion criteria}

- Moderate to significant cognitive impairment

Treatment Strategies:

Hypnosis with imagery and anchoring technique was used for the treatment. The treatment was provided by a single stroke physician trained in the technique and each session lasted for 60 minutes. The audio recording of the sessions were given to the patients to practice daily. The therapy was continued until there was satisfactory control of symptoms or the patient didn't want to continue because of the lack of response.

\section{RESULTS \\ Demography}

Thirty two patients were included for hypnotherapy in this case series.

18 patients had PSA, 5 had insomnia, 4 had PSEI, 3 had PSAP and 2 had PSF.

\begin{tabular}{l|l|l|l|}
\hline Diagnosis & Number of patient & Age( Mean and range) & $\begin{array}{l}\text { Sex ratio } \\
\text { Male) }\end{array}$ \\
\hline PSA & 18 & $\begin{array}{l}49.55 \mathrm{yrs} . \\
(74-26 \mathrm{yrs})\end{array}$ & $13: 5$ \\
\hline Insomnia & 5 & $\begin{array}{l}61.4 \mathrm{yrs} . \\
(43-78 \mathrm{yrs} .)\end{array}$ & $2: 3$ \\
\hline PSEI & 4 & $\begin{array}{l}59.5 \mathrm{yrs} . \\
(34-79 \mathrm{yrs} .)\end{array}$ & $1: 1$ \\
\hline PSAP & 3 & $\begin{array}{l}55.3 \mathrm{yrs} . \\
(45-64 \mathrm{yrs} .)\end{array}$ & $1: 1$ \\
\hline PSF & 2 & $\begin{array}{l}56 \mathrm{yrs} . \\
(49 \text { and } 63 \mathrm{yrs} .)\end{array}$ & Both males \\
\hline
\end{tabular}

On an average, 6 sessions were required to control these symptoms.

Apart from PSF, all the other group of patients self-reported significant improvement in their symptoms. All the patients who responded also reported increased well-being, motivation. More than $90 \%$ of the patients also self-reported satisfactory control of symptoms in the 6 months follow-up. None of the patients reported any side effect.

\section{Conclusions}

$>$ Hypnotherapy showed improvement of the symptoms in PSD, PSEI, PSAP but not in PSF.

- Hypnotherapy can be considered an alternative approach in successfully treating these conditions following stroke.

$>$ The procedure is safe and devoid of any side effect.

\section{REFERENCES}

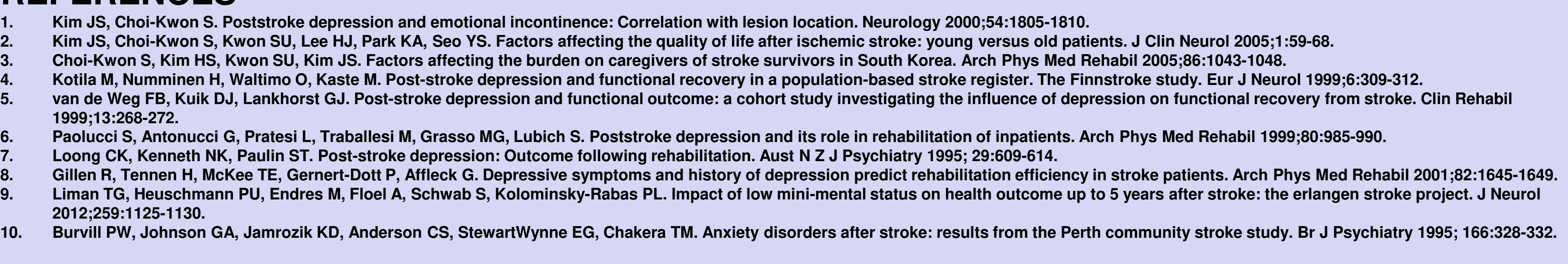

